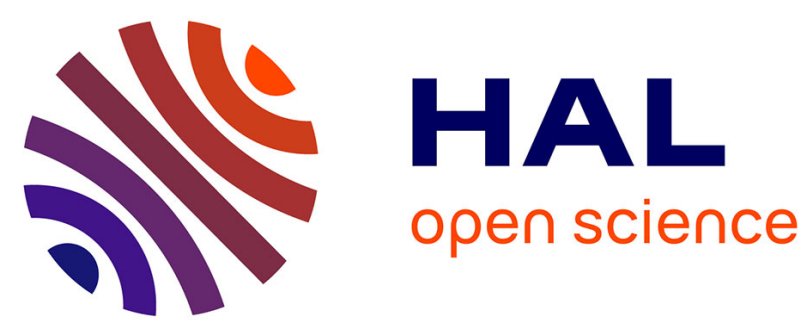

\title{
Expanding small UAV capabilities with ANN : a case study for urban areas observation
}

Rodrigo L. Mota, Luiz F. Felizardo, Elcio H. Shiguemori, Alexandre Carlos Brandao-Ramos, Felix Mora-Camino

\section{- To cite this version:}

Rodrigo L. Mota, Luiz F. Felizardo, Elcio H. Shiguemori, Alexandre Carlos Brandao-Ramos, Felix Mora-Camino. Expanding small UAV capabilities with ANN : a case study for urban areas observation. ICIIP 2013, IEEE Second International Conference on Image Information Processing, Dec 2013, Shimla, India. pp.516 - 520, 10.1109/ICIIP.2013.6707646 hal-01078496

\section{HAL Id: hal-01078496 \\ https://hal-enac.archives-ouvertes.fr/hal-01078496}

Submitted on 29 Oct 2014

HAL is a multi-disciplinary open access archive for the deposit and dissemination of scientific research documents, whether they are published or not. The documents may come from teaching and research institutions in France or abroad, or from public or private research centers.
L'archive ouverte pluridisciplinaire $\mathbf{H A L}$, est destinée au dépôt et à la diffusion de documents scientifiques de niveau recherche, publiés ou non, émanant des établissements d'enseignement et de recherche français ou étrangers, des laboratoires publics ou privés. 


\title{
Expanding Small UAV Capabilities with ANN
}

\author{
A Case Study for Urban Areas Observation
}

\author{
Rodrigo L. Mota ${ }^{\# 1}$, Luiz F. Felizardo ${ }^{\sharp 2}$, Elcio H. Shiguemori ${ }^{* 3}$, Alexandre B. Ramos ${ }^{\sharp 4}$ and Felix Mora-Camino ${ }^{+5}$ \\ \#Institute of Mathematics and Computing, Federal University of Itajubá \\ BPS Av., 1303, Pinheirinho - Itajubá, MG - Brazil \\ *Institute of Advanced Studies, Department of Aerospace Science and Techonology \\ Tamoios Highway, 1, Putim - São José dos Campos, SP - Brazil \\ + Ecole Nationale de l'Aviation Civile \\ 7 Av. Edouard-Belin, CS 54005, Toulouse Cedex 4 -France \\ 1 -rodrigo.mota@unifei.edu.br 2 -1fvarginha@unifei.edu.br \\ 3-elcio@ieav.cta.br 4-ramos@unifei.edu.br \\ 5-felix.mora@enac.fr
}

\begin{abstract}
Autonomous Unmanned Aerial Vehicles (UAVs) are available alternatives for urban areas inspections due to its cost and safety when compared to other traditional methods. The purpose of this paper is to report the development of a system capable of analyzing digital images of the terrain and identifies potential invasion, unauthorized alterations on the ground and deforestation in some areas of special use. Images are captured by a camera coupled to an autonomous helicopter, which flight around the area. For the processing of the images an artificial neural network technique called Kohonen SOM (Self Organized Map) will be used. The processing is actually a set of steps that seek to collate the final common characteristics of a given image.
\end{abstract}

Keywords - Pattern recognition, inspection, UAV, autonomous helicopter, Kohonen SOM

\section{INTRODUCTION}

There has grown enough interest in the use of Unmanned Aerial Vehicles (UAVs) to collect information, initially in the military and more recently also in the civil sector. Due to its low cost, has increased the need to enable UAVs into missions to collect information autonomously, without human intervention.

In many countries currently it is very common to find areas of restricted use, which need to be monitored so as to ensure its integrity by avoiding invasions, deforestation, unauthorized alterations on the ground and etc. The use of UAVs for monitoring has greatly increased in recent years, especially with the combined use of sensor data like Global Positioning System (GPS) and Inertial Measurement Unit (IMU) to perform the registration of the location of the images $[1,2]$.

Given the factors described initially the use of UAV in the inspection of the terrain of transmission lines becomes an attractive alternative. UAVs can travel considerable distances, with higher security and much lower cost than other traditional means could provide, for example, the use crewed helicopters. With factors like fatigue and tiredness due to extensive hours of work the human eye can often fail on the mission of detect a change in the terrain. An autonomous helicopter is able to capture images from different angles, can be then processed by a neural network, so that the locations with the highest probability of finding invasions are spotted.

Artificial Neural Networks (ANN) are based on analogy with the functioning of human brain, where knowledge is maintained through the connections between neurons (synapses). The Kohonen SOM is a kind of competitive neural network with unsupervised learning [3]. For each input signal only the neuron that has the highest affinity with it will be activated. That is, if the inputs of the neural network are the pixels of an image, for each pixel only one neuron is activated by setting the group or class that this pixel belongs. At the end of the process, there is a new output image with pixels grouped according to similar characteristics.

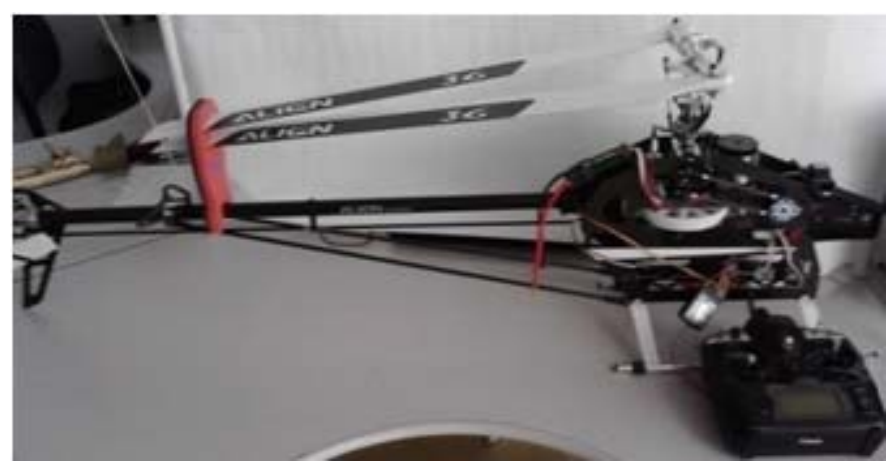

Figure 1 - Chosen Helicopter 
The objective of this paper is to report a system that can analyse images of areas under special situations, and elect (through images) most likely problematic places. The survey currently uses crewed helicopters and is made by human eye analyses, which has a high cost and are likely to miss important failures. Images processed in this case are captured by autonomous helicopters, which greatly reduces the labour and process costs.

\section{HELICOPTER PLATFORM}

\section{A. Aircraft}

The Mini UAV shown in Fig. 1 is a commercial RC helicopter chosen for its price and performance, range, reliability etc. It has a $1.58 \mathrm{~m}$ diameter rotor blade, which is powered by a brushless $700 \mathrm{MX}$ electric, and has a maximum take-off weight of $5.2 \mathrm{~kg}$. The base RC platform weighs $3.2 \mathrm{kgs}$ with batteries, sensors and flight computers. With the basic configuration for GPS waypoint navigation it has an endurance of $30 \mathrm{~min}$. A $2.4 \mathrm{GHz} \mathrm{RC}$ link is used for manual flight and a $2.4 \mathrm{GHz}$ wireless modem is used to transmit telemetry data to the ground station and operator commands from the ground station. This link together with the omnidirectional antennas used has a line-of-sight range of approximately $5 \mathrm{~km}$ but if by any means the link is lost an automatic return home procedure will take command of the aircraft bringing it back to visual sight of the operator.

\section{B. Autonomous Flight}

All the sensors used for autonomous flight are included in a commercial integrated device, including an IMU, GPS receiver, magnetometer and barometer, see Fig. 2. The device fuses the sensor data with an Extended Kalman Filter to produce a filtered state estimate of position. The on-board flight computer uses the state estimate to generate appropriate commands for autonomous flight in the form of Pulse-Width Modulation (PWM) signals which is converted to PulsePosition Modulation (PPM) signal through a PPM encoder board. These are fed to the servos via Lisa/M board. This board can select between pilot RC commands or flight computer commands passing through to the servos, allowing switching between manual, autonomous stabilization and complete autonomous flight.

The current control strategy is implemented using standard techniques. Inner Proportional Integral Derivative (PID) loops control attitude at a high update rate, while outer loops control position and velocity at a lower rate. The PID gains have been tuned for airspeeds up to $10 \mathrm{~m} / \mathrm{s}$ through flight trials and system identification. This control implementation provides reliable hover (within the error bounds of the GPS receiver), and has been used for forward flight with airspeeds of up to $18 \mathrm{~m} / \mathrm{s}$. Although the controller performs well in winds with fairly constant speeds, it is not yet optimised for gusts and turbulence [4].

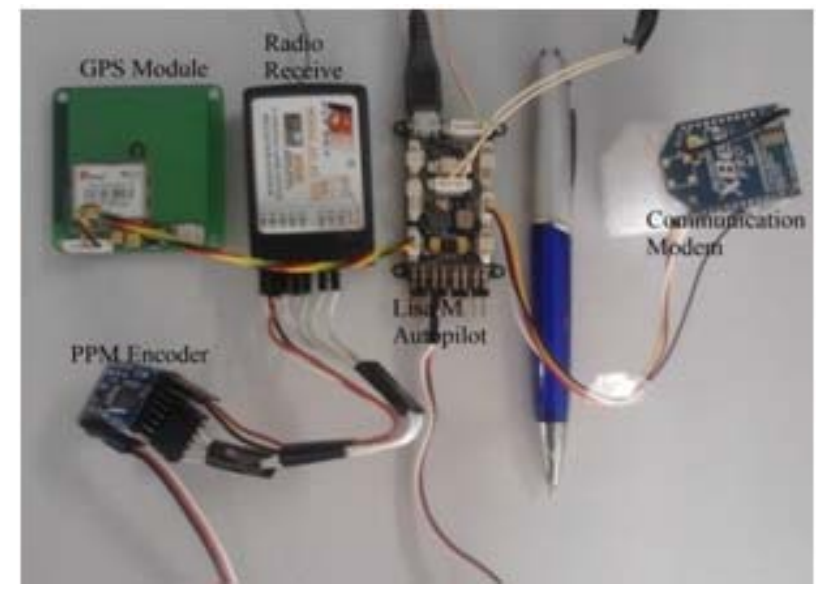

Figure 2 - Hardware Embedded in the Helicopter.

\section{GROUND STATION}

The software used in this project for aerial control is called Paparazzi is a free and open-source hardware and software project [5] intended to create an exceptionally powerful and versatile autopilot system for fixed-wing aircrafts as well as multicopters by allowing and encouraging input from the community, showed in Fig. 3. Many changes were made in its code for supporting our helicopter. The Paparazzi project includes not only the airborne hardware and software, from voltage regulators and GPS receivers to Kalman Filtering code, but also a powerful and ever-expanding array of ground hardware and software including modems, antennas, and a highly evolved user-friendly ground control software interface.

The versatile Paparazzi Ground Control Station is an operator control unit ground control software for micro air vehicles. It allows visualizing and controlling a micro air vehicle during development and operation. With a flexible software architecture it supports multiple aircraft types/autopilot projects. The purpose of the ground control station is to have a real-time monitoring of an UAV [6].

It allows the user to change in-flight parameters such as the throttle speed, altitude and others. Not only that but it shows flight information like batteries level, current altitude, ground speed, air speed and the top view map. With a simple mouse click the user can change a waypoint location or switch to some other pre-defined route. Figure 3 shows a screenshot of the interface. 


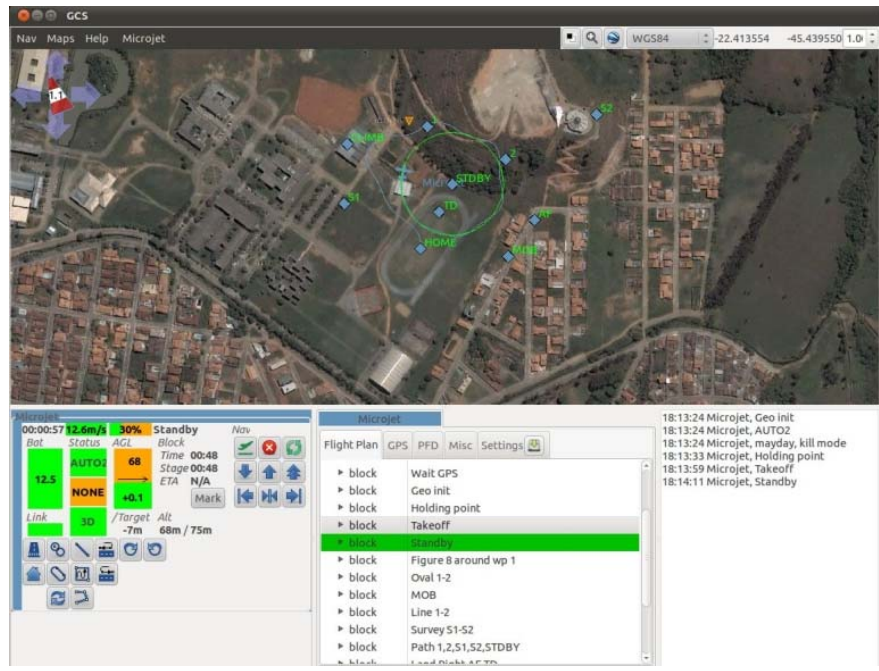

Figure 3 - Ground Control Station Interface.

\section{IMAGE PROCESSING}

A system for processing images (see Fig. 4) generally has the following parts [7]:

- Image acquisition: consists of a sensor to acquire the image and a second element capable of digitizing the signal, generating a digital image.

- Pre-processing: has the function to improve the image, seeking to increase the chances of success for the following procedures. Involves techniques for contrast enhancement, noise removal and region isolation;

- Segmentation: divides an input image into parts or objects. It is one of the most difficult automatic processes in image processing. The output of this stage is usually given in the form of pixels, corresponding to the boundary of a region or its constituent points;

- Representation and description: this stage of processing the data is transformed appropriately for the computational processing that follows, being stressed characteristics of interest. The process of description, also called selection of characteristics, have extracted characteristics that represent quantitative information of interest or which are fundamental in the discretion of classes and objects;

- Recognition: recognition is the process that assigns a label to an object and interpretation involves the assignment of meaning to a set of recognized objects.

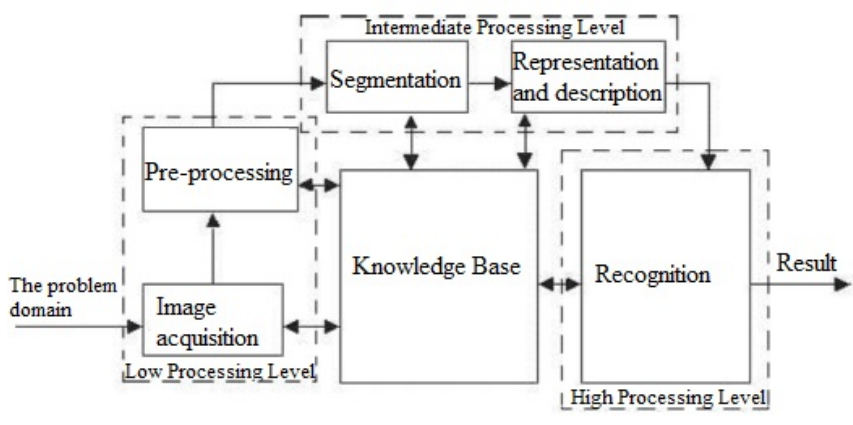

Figure 4 - Image Processing Division.

\section{KOHONEN SELF-ORGANIZING MAP}

The Kohonen Self Organizing Map (SOM) is a map or matrix with non-symmetric dimension, where each element represents a neuron [8]. Neurons are interconnected and maintained relation to each other, even influencing each other. Each neuron or set of neurons represents an output and is responsible for a particular function. This feature is analogous to the brain where different information are controlled by different parts of the brain, such as speech, hearing and vision. The artificial neural network resembles other brain aspects such as: knowledge acquisition from the environment through a learning process and connection strengths between neurons the synaptic weights - which are used to store the acquired knowledge.

The goal of SOM is the classification of the input data as the knowledge that neurons acquire. The topology between input and output is always kept, since the notions of neighbourhood between neurons are not altered.

The synaptic weights are initialized randomly and during learning such weights will be updated at each iteration of the algorithm. The intention of this phase is to find the neuron that has the closest characteristics of the input. Thus, after a process of iteration only one neuron is activated, however their neighbours also suffer a small influence.

\section{A. SOM Kohonen Algorithm}

1. Randomize the map's nodes' weight vectors

2. Grab an input vector

3. Traverse each node in the map

3.1 Use Euclidean distance formula to find similarity between the input vector and the map's node's weight vector

3.2 Track the node that produces the smallest distance (this node is the Best Matching Unit, BMU)

4. Update the nodes in the neighbourhood of BMU by pulling them closer to the input vector

$$
4.1 W v(t+1)=W v(t)+\Theta(t) \alpha(t)(D(t)-W v(t))
$$

5. Increase $t$ and repeat from 2 while $t<\lambda$

where:

$t$ denotes current iteration.

$\lambda$ is the limit on time iteration.

$W v$ is the current weight vector.

$D$ is the target input.

$\alpha(t)$ is a monotonically decreasing learning coefficient. 
(t) is restraint due to distance from BMU, usually called the neighbourhood function, and is learning restraint due to time [9].

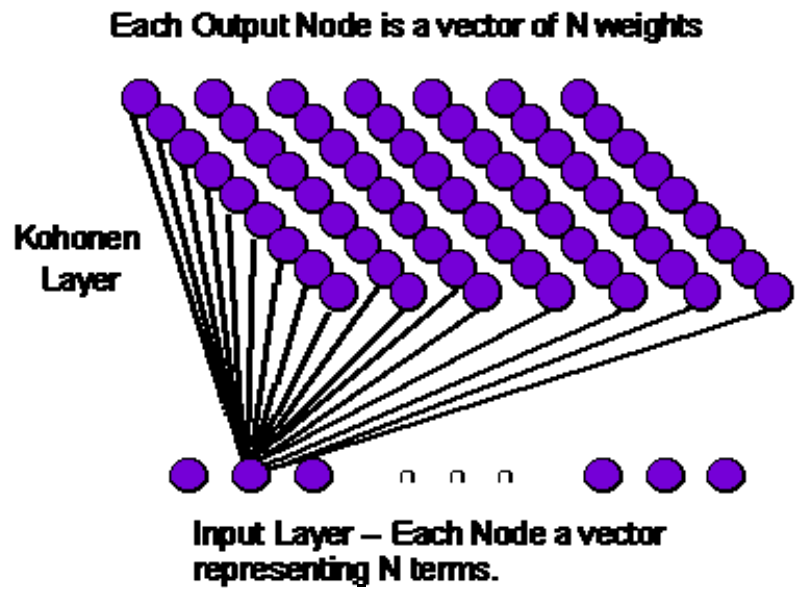

Figure 5 - Kohonen SOM Topology.

The topology of the Kohonen SOM network is shown in Fig. 5. This network contains two layers of nodes - an input layer and a mapping (output) layer in the shape of a twodimensional grid $[9,10]$.

\section{EXPERIMENTS AND RESULTS}

A Java software that implements the Kohonen SOM was developed. It allows one image to be inputted and generates a new output image where the pixels are grouped according to similar features.

For the processing some parameters must be set. These parameters are linked to which type of sensor to capture images is being used. For example, the optimal parameters for images captured by an UAV are not the same as satellite images. These parameters are:

- Number of iterations: how many times the algorithm will be repeated. Typically the higher the number of iterations the higher is the quality of the processing. However, after a certain point the number of iteration starts to damage the quality of the output image. Thus, an intermediate number should be fit so that the quality is not compromised.

- Rate of learning: learning rate interferes with the updating of synaptic weights. A very small learning rate requires a higher number of iterations to converge to the desired result. However, a very high rate causes oscillations and also hampers convergence.

- Number of neurons: each neuron represents a class, i.e., a distinct characteristic. The number of neurons must be placed according to how the user wants to have some generalization in the grouping of neurons. The smaller the number of neurons more generalist will be the grouping. A very high number of neurons will tend to cause the output to copy the entry, which is not desired.

To test the Kohonen SOM and better understand its operation some tests were made using aerial images of a city. Table 1 below shows the parameters used in the configuration.

TABLE

KOHONEN SOM TEST

\begin{tabular}{|c|c|c|c|}
\hline Test \# & $\begin{array}{c}\text { Number of } \\
\text { Iterations }\end{array}$ & $\begin{array}{c}\text { Learning } \\
\text { Rate }\end{array}$ & Number of Neurons \\
\hline Test 0 & 3 & 0.000001 & $2 \times 1$ \\
\hline Test 1 & 4 & 0.000001 & $2 \times 1$ \\
\hline Test 2 & 5 & 0.000001 & $2 \times 1$ \\
\hline Test 3 & 6 & 0.000001 & $2 \times 1$ \\
\hline Test 4 & 7 & 0.000001 & $2 \times 1$ \\
\hline
\end{tabular}

The sequences of steps taken to implement the tests are:

1. The images were converted to grayscale.

2. An adjustment in brightness and color tone of the images was made.

3. The image is processed by the software that uses a Kohonen neural network.

Below we can see in the Fig. 6 to 9, an example of test number two.

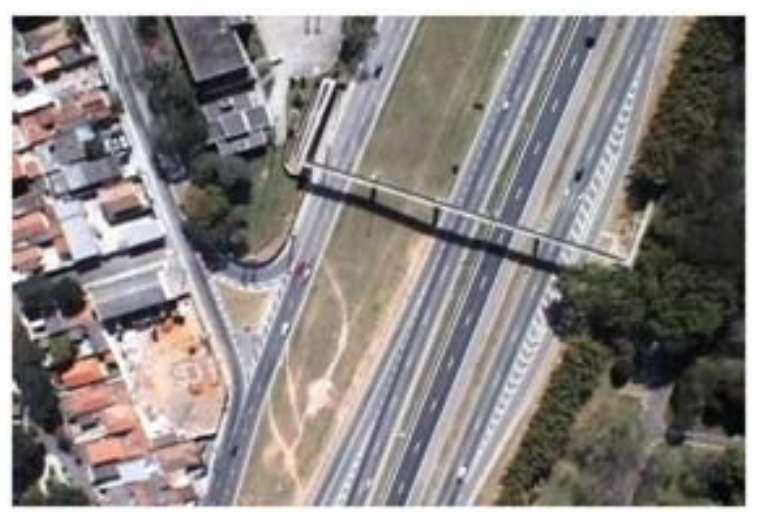

Figure 6 - Original Image Captured by the UAV.

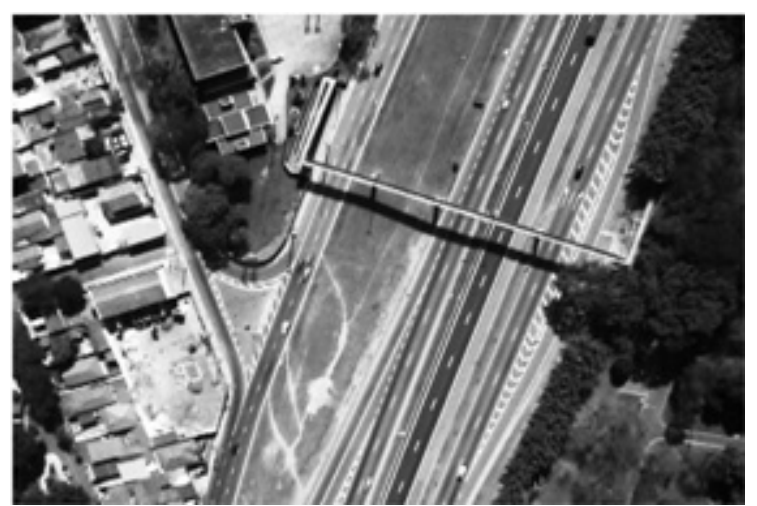

Figure 7 - Image After the Application of Step 1. 


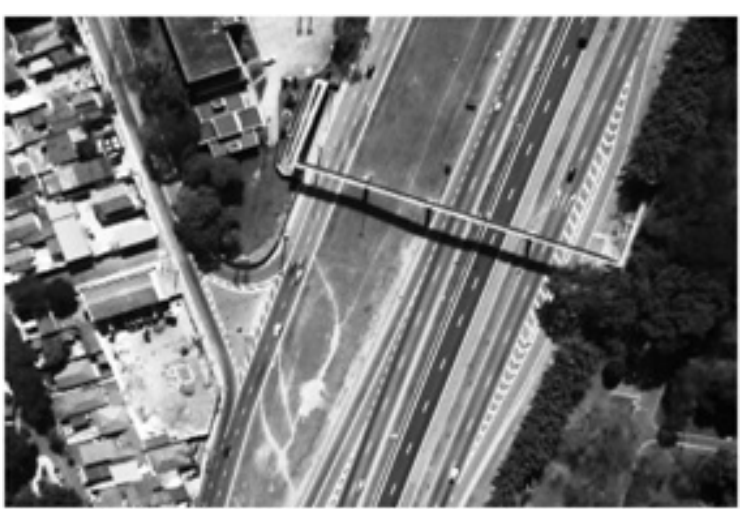

Figure 8 - Image After Brightness Change From Step 2.



Figure 9 - Image After All 3 Steps.

The tests were made using only two neurons, one representing the white color and other representing the black color. Steps one and two correspond to a pre-processing, which assist the image processing done by Kohonen SOM in step 3. The pre-processing makes it easier to the final process recognizing which color is closer to white and which closer to black.

\section{CONCLUSIONS AND FUTURE WORK}

The Kohonen SOM allows grouping the pixels of an image with similar characteristics. In the case of this work, the pixels become widespread in two classes - white and black. After processing, there is a new output image with the colors rearranged. The same process can be used for finding faults in transmission lines in all three spectrums mentioned in this article.

UAVs are already being used in many fields today and will certainly be largely used for transmission line inspection, future works include but are not limited to improvements on the autopilot system for a better stability on gusty conditions and the usability of an airplane instead of a helicopter for other uses that require long and faster distances travelling.

\section{ACKNOWLEDGMENT}

The authors thank the National Council for Scientific and Technological Development of Brazil (CNPq) for support of this work under contract number 238348/2012-1, $310031 / 2012-5$ and 470186/2012-7.

\section{REFERENCES}

[1] Y. Wang, R. R. Schultz and R. A. Fevig. "Sensor fusion method using GPS/IMU data for fast UAV surveillance video frame registration". IEEE International Conference on Acoustics, speech and signal processing - ICASSP 2009. pp 985-988.

[2] E. Semsch, M. Jakob, D.Pavlíćek and M. Pěchouček. "Autonomous UAV surveillance in complex urban environments". International Conference on Web Intelligent Agent Technology Workshop 2009 IEEE/WIC/ACM.pp 82-85.

[3] S. Hrabar, T. Merz, and D. Frousheger, "Development of an autonomous helicopter for aerial powerline inspections," 2010 1st International Conference on Applied Robotics for the Power Industry (CARPI 2010), pp. 1-6, Oct. 2010.

[4] S. Haykin, Self-organizing maps. Neural networks - A comprehensive foundation, 2nd ed. Prentice-Hall, 1999.

[5] "Paparazzi Project Webpage," 2012. [Online]. Available: http://paparazzi.enac.fr/wiki/Main_Page. [Accessed: 15-Jun-2012].

[6] "Paparazzi Project Webpage, Ground Control Station," 2012. [Online]. Available: http://paparazzi.enac.fr/wiki/GCS. [Accessed: 12-May-2012].

[7] R. C. Gonzales and E. R. Woods, "Processamento de Imagens Digitais". São Paulo, Brasil: Editora Edgard Blücher, 2000 .

[8] A. Machado, Neuroanatomia Funcional. Livraria Atheneu, 1980.

[9] M. Caudill, A little knowledge is a dangerous thing. AI Expert. pp. 8(6):16-22.

[10] A. Hiotis, Inside a self-organizing map. AI Expert. pp. 8(4):38-43. 